\title{
Benchmarking Profitability Derivatives of Labour Cost in Boatyards for a Sustainable Coastal Environment in Nigeria
}

\author{
Ibeawuchi C. Nze
}

\section{ABSTRACT}

The research benchmarks the profitability derivatives of labour cost of boatyards for a sustainable coastal environment in Nigeria so as to proffer solutions towards ameliorating wage increase agitations by workers of boatyards. Using the Linear Programming (LP) approach applied to the extracted information on selling price of various boat types and the cost of materials available in the records of the selected boat yard, a model is formulated and solved to attain optimality for the boat types modeled. The findings reveal that boat yards in the area could produce 6 units of the Nineteen Capacity Passenger Boat (NCPB), 1 unit of the Twenty three Capacity Passenger Boat (TCPB) and 0 unit of the Twenty three Carrier Boat (TCCB) in order to attain an optimal profit of $\mathrm{N1}, 098,000$. 00 per unit boat built. The research impact would be that boat building firms within the coastal environment may enjoy profit margins up to $\mathrm{N386,000.00}$ when compared to the previous firm's total profit of $\mathbf{N 7 1 2 , 0 0 0 . 0 0}$. This is supported by the sensitivity analysis that reveals that increased labour cost has no significant effect on the profit margin of the firm. This justifies the increased wage agitation by workers which could be considered by the firm's management. The practical impact would be felt on the overall productivity of the boat yard as there is a maximized profit margin and minimized wastage of component materials in the boat building process. The firms would concentrate on the production of the NCPB and TCPB against the production of TCCB because the agrarian and coastal nature of the Niger delta pre supposes a push in the demand for passenger transportation against heavy cargo transportation which is costly and left in the hands of few wealthy and Multinational companies that could afford heavy building construction as well as industrial plants. It is further recommended that boatyards within the coastal environment and Niger delta should leverage on this benchmark to continuously embark on profit maximization while reducing wastage of component materials and cost as low as possible which ultimately would lead to a sustainable coastal environment in respect of small craft design.

Keywords: Benchmarking, boatyard, cost, coastal environment, profitability, sensitivity.

Published Online: July 30, 2020

ISSN: $2684-446 \mathrm{X}$

DOI : $10.24018 /$ ejgeo.2020.1.4.19

I. C. Nze*

Maritime Management Technology

Department, Federal University of

Technology, Owerri, Nigeria.

(e-mail: elibechibu@yahoo.com)

\section{INTRODUCTION}

Profit maximization is the goal of every business venture. Profitability therefore is a derivative of well thought ideas executed through a sound managerial skills and blend with optimal components in production process, at reduced production cost and material wastage which ultimately leads to a marketable product. It is not out of place to assert that the building process of Boats is becoming increasingly complex as more subsystems of approaches are being considered and the various components of production processes are taken into consideration to improving not only local but small and medium scale production of Boats at an improved production mix. This may reduce costs associated with the production processes. This paper tends to address the problem of wastages in material allocation of the raw material resources in the production process in the manufacturing of marine Boats. Some Boat Building firms situated within the coastal areas and the Niger delta were used as a case study due to inconsistencies in profit margins of the boat building firms and to address workers agitations for improved wages. Several optimization models, including linear programming, have been applied to the product mix selection problem. Since its development, Linear programming (LP) theory and related solution techniques have been widely extended and used as an optimization tool in a variety of problem areas including the production planning and product mix selection areas. [1], posits that many other optimization decisions can be well solved by modern linear programming modeling procedures via appropriate problem formulation and equation fittings. In furtherance, [2] gives an insight into the technical background as well as practical applications of the new regulation for structural optimization with respect to the impact on the marine industry. The study also reveals applicability extending up to 24 meter load line with the use 
of finite element methods. In the same vein, [3] adopted Bifilar yaw moment measurement in the construction of sailing boats which pre supposes accurate measurement of the length, 1 and spacing, $2 \mathrm{~d}$ of the suspension and of $\mathrm{T}_{\mathrm{y}}$, the period of yaw oscillation. [4] propose the modeling and control of a tethered kite in dynamic flight which attempts to provide ships with an alternative green energy source by designing an auto- pilot to control a kite that can generate enough power to tow a ship. This would hence provide ships with an alternative green energy options. However, [5] explains that decision-making in product mix selection could be difficult due to large number of possibilities involved, implying that resource limitation could make decision difficult to meet customer demand and hence reduce the opportunity to earn profits. To this end, some critical questions would guide the analysis and discussion in this research:

To what extent would material mix for the production of each boat attain optimal profit?

What is the effect of wage increase on the firm's profit margin?

In the light of the above, this study attempts the application of linear programming Techniques to the manufacturing of Marine Boats using indigenous available resources in order to maximize the profit within the aforementioned constraints so as to minimize cost and wastage of materials; hence more profitability derivatives achieved by the firm. The Specific Objectives include:

To attain the optimal profit level with materials mix and labour that reduces wastage and cost in the boatyard.

To reveal the effect of wage increase of the workers on the firm's profit margin.

\section{LITERATURE REVIEW}

\section{A. Conceptual Review}

Resource scarcity is a major constraint in any firm's decision regarding optimal products mix as well as profit maximization [6]. They affirm that many other optimization decisions could be well handled by modern linear programming modeling procedures via appropriate problem formulation and equation fittings. In a related study, [5] posits that the decision-making in product mix selection is difficult due to large number of possibilities involved which included the limitation of resource capacities that further makes it difficult to meet customer demand and hence reduces the opportunity to earn profits. Thus several optimization models, including linear programming, have been applied to the product mix selection problem. Hence, [7] refer to linear programming as a 'single objective constrained optimization technique' which seeks a single objective of either minimizing or maximizing unknown variables in a model.

\section{B. Theoretical Review}

In line with this and in an earlier study, [8] argue that linear programming deals with linear optimization of a function of variables known as objective function subject to set of linear equations and /or inequalities known as constraints. They assert that the objective function may be profit, cost, production capacity or any other measure of effectiveness which is to be obtained in the best possible or optimal manner. The constraints may be imposed by different resources such as market demand, production process and equipment storage capacity, raw material availability etc.

In furtherance, [9] affirms that linear programming is of great use in making business decision because it helps in measuring complex economic relations and thereby, provides an optimum solution to the problem of resource allocation and thus, bridges the gap between abstract economic theories and managerial decision-making. This theory was applied to the marketing strategy of New Energy Vehicles in SL company and thus provides better suggestions for enterprise managers for the promotion a larger market share for the new energy automobile enterprise.

\section{Empirical Review}

Corroborating this view, [10] had earlier on given the general specification of the linear programming model by obtaining solutions of Linear Programming Problems by the segmentation of the cuboidal response surface through the Convergent Line series methodologies and later on, [11] applied optimization techniques in pushing native shipping industrial integration as an important route to posses the advantages of the scale economy, in order to foster the leading enterprise.

\section{Materials And Methods}

\section{A. Sources of Data}

Data required for this study were collected from secondary sources. Secondary source of data was a survey of existing documents and published materials relating to the operations of the sampled boatyards.The data set used for this work was collected as extract from their records on the production of the three boat types: the Nineteen Capacity Passenger Utility Speed boat (NCPB), Twenty three Capacity Passenger Utility Speed boat (TCPB) and Twenty three Capacity Carrier boats (TCCB) respectively.

\section{B. Method of Data Analysis and Modeling}

In order to provide empirical answers to the research questions, the Linear programming technique is applied by the use of Excel Solver for windows software for the analysis. The marketing approach of the company is to ensure a relative optimization in the selling price and profit per unit purchase of each boat to users, government agencies and companies on demand. This design is to encourage wholesale (large purchases of boats for the Maritime transportation of goods and passengers) of the marine boats for increased profitability.

\section{Variable Definitions}

The generalized variables form for linear programming problem is stated as:

$$
\begin{aligned}
& \text { Maximize } Z=a_{11} X_{1}+a_{12} X_{2}+a_{13} X_{3} \leq r_{1 t} \\
& \text { Subject to } \\
& a_{12} X_{1}+a_{12} X_{2}+a_{13} X_{3} \leq r_{1 t} \\
& \mathrm{a}_{21} \mathrm{X}_{1}+\mathrm{a}_{22} \mathrm{X}_{2}+\mathrm{a}_{23} \mathrm{X}_{3} \leq \mathrm{r}_{2 \mathrm{t}} \\
& \mathrm{a}_{31} \mathrm{X}_{1}+\mathrm{a}_{32} \mathrm{X}_{2}+\mathrm{a}_{33} \mathrm{X}_{3} \leq \mathrm{r}_{3 \mathrm{t}} \\
& \mathrm{a}_{41} \mathrm{X}_{1}+\mathrm{a}_{42} \mathrm{X}_{2}+\mathrm{a}_{43} \mathrm{X}_{3} \leq \mathrm{r}_{4 \mathrm{t}}
\end{aligned}
$$




$$
\begin{aligned}
a_{51} X_{1}+a_{52} X_{2}+a_{53} X_{3} & \leq r_{5 t} \\
a_{61} X_{1}+a_{62} X_{2}+a_{63} X_{3} & \leq r_{6 t} \\
a_{71} X_{1}+a_{72} X_{2}+a_{73} X_{3} & \leq r_{7 t} \\
a_{81} X_{1}+a_{82} X_{2}+a_{83} X_{3} & \leq r_{8 t}
\end{aligned}
$$

where $\mathrm{X}_{1}, \mathrm{X}_{2}, \mathrm{X}_{3}, \ldots \mathrm{X}_{\mathrm{n}} \geq 0$

Then $c_{j}$, and $r_{j}$ are given constraints, the variables $X_{1}, X_{2}$, $\mathrm{X}_{3}, \ldots \mathrm{X}_{\mathrm{n}}$ are called decision variables. The problem is to find the values of the decision of the $\left(X_{1}, X_{2}, X_{3}, \ldots X_{n}\right)$ which maximize the objective decision variables or which maximizes the objective function in order to produce the optimal solution. This procedure is called the simplex Algorithm where:

$\mathrm{Z}=$ total profit contribution of the various products of the company for the period.

$\mathrm{C}_{\mathrm{i}}=$ profit contribution coefficient i.e the numeric values that express the per unit contribution to the profit equation.

$\mathrm{X}_{1} \ldots \mathrm{Xn}=$ the set of unknown we are seeking to determine i.e the various products (boats) produced by company

$\mathrm{a}=$ technological coefficients i.e. the numeric value that expresses the per unit usage of the right hand size

$r_{1} \ldots r_{n}=$ the resources value that we seek to fully utilize in the production.

$\mathrm{t}=$ the maximum labour time available for the production period in the yard

$t_{1} \ldots t_{n}$ the labour time required to produce one unit of the various products of the boatyard.

\section{Decision Variables}

$\mathrm{X} 1$ = the quantity of Nineteen Capacity Passenger Boat (NCPB) to be Produced

$\mathrm{X} 2$ = the quantity of Twenty three Capacity Passenger Boat (TCPB) to be Produced

$\mathrm{X} 3$ = the quantity of Twenty three Capacity Carrier Boat (TCCB) to be Produced

The Profit Contribution coefficient given as the numerical values that express the per unit contribution to the profit equation are stated as:

$\mathrm{P} 1$ = the average net contribution by one unit of Nineteen Capacity Passenger Boat (NCPB).

$\mathrm{P} 2$ = the average net contribution by one unit of Twenty three Capacity Passenger Boat (TCPB).

P3 = the average net contribution by one unit of Twenty three Capacity Carrier Boat (TCCB)

\section{E. Model Formulation}

In the model, technological coefficients represent the numerical values that expresses per unit usage of the various raw materials in the production of the various products.

$\mathrm{C}_{11}=$ Cost of laminating and fitting materials in producing one unit of Nineteen Capacity Passenger Boat (NCPB).

$\mathrm{C}_{21}=$ Cost of woven materials in producing one unit of Twenty three Capacity Passenger Boat (TCPB).

$\mathrm{C}_{31}=$ Cost of laminating materials and fitting in producing one unit of Twenty three Capacity Carrier Boat (TCCB).

Labour time here represents the time needed to produce one unit of the various products of boat construction as follows:

$\mathrm{t}_{1}=$ the labour time in hours required to produce one unit of Nineteen Capacity Passenger Boat (NCPB).

$\mathrm{t}_{2}=$ the labour time in hours needed to produce one unit of Twenty three Capacity Passenger Boat (TCPB).

$\mathrm{t}_{3}=$ the labour time required to produce a unit of Twenty three Capacity Carrier Boat (TCCB).

$\mathrm{T}$ = Maximum labour time available for the production.

These represent the resource values that we seek to be fully utilized. For instance,

$\mathrm{C}_{1}=$ the amount of money available within the production period for the purchase of laminating and fitting

$\mathrm{C}_{2}=$ the amount of money available for the purchase of woven

$\mathrm{C}_{3}=$ the amount of money available for the purchase of resin

B4 = the amount of money available for the purchase of catalyst

$\mathrm{C}_{5}=$ the amount of money available for the purchase of Pigment.

$\mathrm{C}_{6}=$ the amount of money available for the purchase of Accelerator.

$\mathrm{C}_{7}=$ the amount of money available for the purchase of Clear gel.

$\mathrm{C}_{8}=$ the average amount of money available for wages.

TABLE I: SUMMARY OF VARIABLES RELATIONSHIP

\begin{tabular}{|c|c|c|c|c|c|}
\hline $\begin{array}{c}\text { Profit } \\
\text { contributi } \\
\text { on }\end{array}$ & $\begin{array}{c}\mathrm{N} 140,2 \\
00\end{array}$ & $\begin{array}{c}\mathrm{N} 256,0 \\
00\end{array}$ & $\begin{array}{c}\mathrm{N} 315,0 \\
00\end{array}$ & \\
\hline $\begin{array}{c}\text { Boat } \\
\text { Model }\end{array}$ & NCPB & TCPB & TCCB & $\begin{array}{c}\text { Availa } \\
\text { ble }\end{array}$ \\
\hline 1. & $\begin{array}{c}\text { Fabricati } \\
\text { ng }\end{array}$ & 40 & 60 & 80 & 300 \\
\hline 2. & Woven & 25 & 50 & 60 & 200 \\
\hline 3. & Resin & 110 & 220 & 330 & 1000 \\
\hline 4. & Catalysts & 5 & 10 & 15 & 200 \\
\hline 5. & $\begin{array}{c}\text { Accelera } \\
\text { tor }\end{array}$ & 2 & 3 & 5 & 30 \\
\hline 6. & Pigment & 3 & 3 & 4 & 40 \\
\hline 7. & Clear gel & 20 & 22 & 40 & 200 \\
\hline 8. & $\begin{array}{c}\text { Labour } \\
\text { constrain } \\
\mathrm{t}\end{array}$ & 20,000 & 30,000 & 40,000 & 300,000 \\
\hline 9. & $\begin{array}{c}\text { Time } \\
\text { constrain } \\
\mathrm{t}\end{array}$ & 48 & 96 & 168 & 210 \\
\hline
\end{tabular}

Source: TUWASCO Marine and Boat Building Company

TABLE II: UNIT PROFIT CONTRIBUTION BY BOAT TYPES

\begin{tabular}{|c|c|c|c|}
\hline Boats & Production cost & Selling price per boat & Profit \\
\hline $19 \mathrm{PU}$ & 309,800 & 450,000 & 140,200 \\
\hline $23 \mathrm{Pu}$ & 493,200 & 750,000 & 256,800 \\
\hline $23 \mathrm{C}$ & 685,000 & $1,000,000$ & 315,000 \\
\hline
\end{tabular}

Source: Computation based on field work in [11]

The linear programming model for the boat building is formulated thus:

Maximize

$140,200 \mathrm{x}_{1}+256,000 \mathrm{x}_{2}+315,800 \mathrm{x}_{3}$

Subject to: raw material and labour constraints

Fabricating materials $400 \times_{1}+600 \times_{2}+50 \times_{3} \leq 300$

Woven Material

Resin

$25 \mathrm{X}_{1}+50 \mathrm{X}_{2}+60 \mathrm{X}_{3} \leq 200(10)$

$110 X_{1}+220 X_{2}+330 X_{3} \leq 1000(11)$ 
Catalyst

$5 \mathrm{X}_{1}+10 \mathrm{X}_{2}+15 \mathrm{X}_{3} \leq 200$

Pigment

$3 X_{1}+3 X_{2}+4 X_{3} \leq 40$

Accelerator

$2 X_{1}+3 X_{2}+5 X_{3} \leq 30$

Clear gel

$20 X_{1}+22 X_{2}+40 X_{3} \leq 200$

Labour

$\underset{\leq 300,000}{20,000 \mathrm{X}_{1}+36,000 \mathrm{X}_{2}+40,000 \mathrm{X}_{3}}$

$X_{1}, X_{2}, X_{3, \ldots}, X_{n} \geq 0$

\section{RESULTS}

The following results are presented and analyzed thus to attempt an answer to the earlier research questions for this study.

The model produced an optimal solution satisfying all the optimality conditions for the Boat Building company.Results reveal that 6 units of the Nineteen Capacity Persenger Boat (NCPB) should be produced,1unit of the Twenty three Capacity Passenger Boat (TCPB)should be produced and no unit of the Twenty three Capacity Carrier Boat (TCCB) should be produced with a total objective function of N1,098,000.

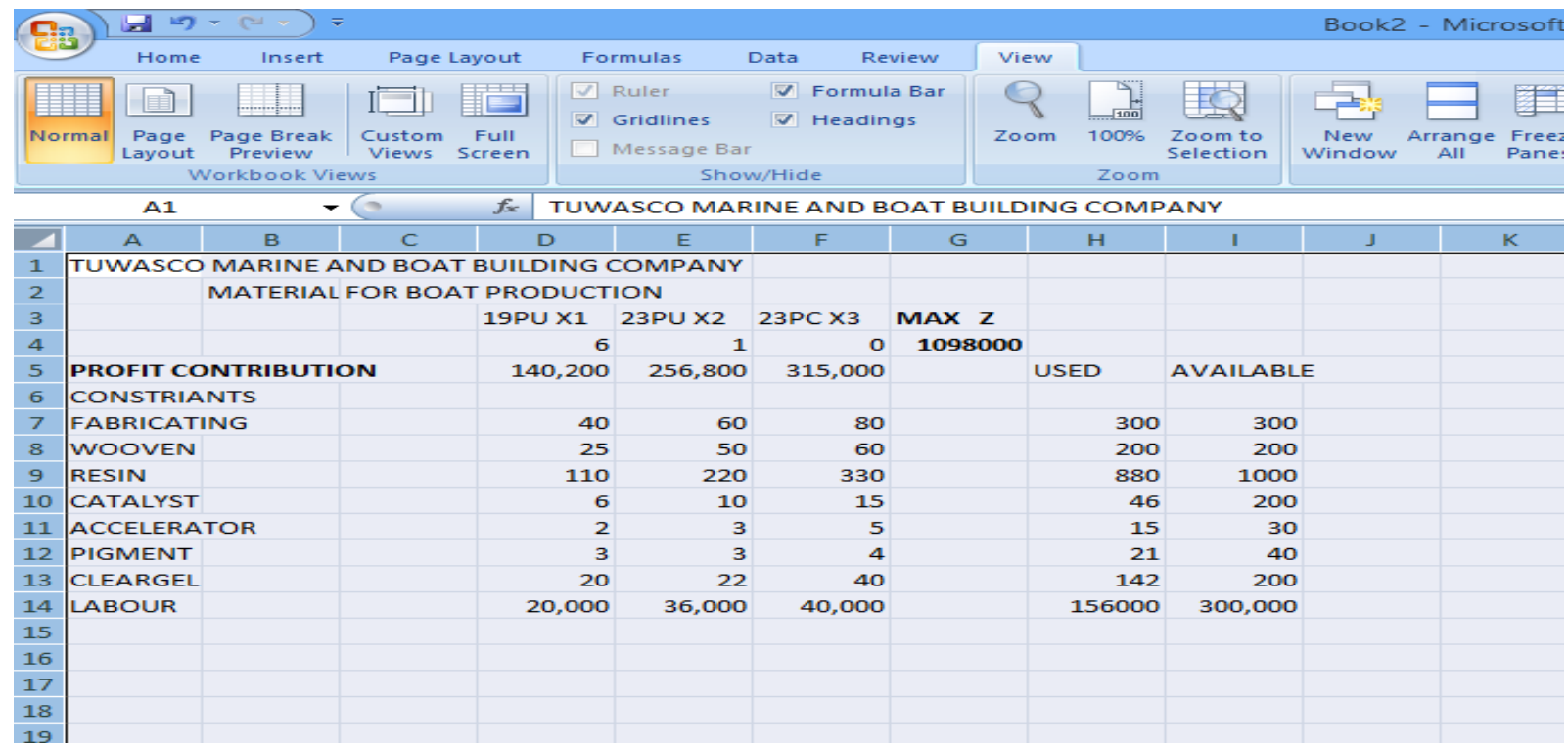

Fig. 1. Optimal solution of the LP problem

On the other hand, fabricating/ laminating constraints and the woven constraints have a slack of Zero (binding constraints) in that they both satisfy the optimality conditions. The implication is the possibility of acquiring more of the Fabricating/laminating materials and the woven materials for an improved objective function. Other constraints like the Resin, accelerator, catalyst ,pigments, labour and clear gel did not satisfy the optimality of the LP and such are regarded as loose or non binding constraints. These are constraints in the LP whose changes do not affect the optimal solution. Non binding constraints have a shadow price of zero.

\section{A. Sensitivity Analysis}

The labour cost of was doubled in the Tuwasco Marine and Boat building Model. Specifically, the labour cost for producing the Nineteen Capacity Passenger Boat (NCPB) was increased from $\mathrm{N} 20,000$. 00 for two staff to $\mathrm{N} 40,000.00$ and from N36,000.00 to N72,000.00 for the Twenty three Capacity Passenger utility boat (TCPB), and from N40,000.00 to N80,000.00 for the building of the Twenty three Carrier Boat (TCCB) due to agitation for increased wages. The result shows a corresponding effect on the objective function of the Company. The implication is that even at increased labour cost to the company arising from wages, there was no significant effect/change on the objective function of the boat building model. This addresses staff agitation for improved and increased wages.

One of the key component material needed for the production of boat- resin- was reduced by half, for the Nineteen Capacity Passenger boat that is from 110 units to 55units and for the Twenty three Capacity Passenger utility boat, it was reduced from 220 units to 110 units. Then for the 23 Capacity Carrier boat it was reduced from 330units to 165 units, and optimality was attained satisfying all the constraints with the following outcome.

The total optimized profit increased from N1,098,000.00 to N1,199,454.55 with boat producing capacity of 3 for the Nineteen Capacity Passenger Boat and 3 for the Twenty three Capacity passenger Boat and none for the Twenty three Capacity Passenger Boat as well. The fabricating and laminating constraints and resin constraints became binding constraints. This implies a surplus material mix on resin, thus reducing wastages as other constraints were not binding.

\section{Discussion}

Solution of the LP offered by the software as shown in the figure 1, gives optimal profit level of the company to be $\mathrm{N} 1,098,000.00$ as against its former profit level of N721,000.00. This results in a profit improvement of N377,000.00 meaning that, for optimal profit operations, Boat Building firms in the coastal areas of Niger delta 
should keep profit level of N1,098,000.00 based on the available resources. This study, having produced a mathematical model that attained optimal solution by maximizing the total profit of the company, falls in line with the work of [12] that applied a simulation approach to designing Sails against an earlier experimental approach, and thus presents a solver that couples CFD and FEM in order to compute a deformed sail shape with the resulting thrust.

The optimal solution for the boatyard as derived from the model developed is given as: NCPB $\mathrm{x} 1=6$ boats, TCPB $\mathrm{x} 2$ $=1$ boat, $\mathrm{TCCBx} 3=0$ with an improved objective function of N1,098,000. This implies that the company should concentrate its resources to the production of six (6) NCPB and one (1) 2TCPB model and no resources should be plunged on the production of TCCB except on special demand. This is related to the work of [13] which evaluated the scaling up, performance and safety of the Philippine indigenous outrigger boat, and reports that the boats vary in size from 4 meter single crew paddle boats to large 50 meter fishing vessels and passenger ferry boats.

For each constraint the shadow prices reveal exactly how much the objective function will change with a change in the right hand side of the corresponding constraint equation. For example, in the fabricating constraint equation, the optimality range is between 320 and 240 respectively while the objective function would be exactly 1180 (i.e. given a change in the right hand side from 300). Similarly, for woven materials costs, provided the right hand side of the constraints remain between 227.2727 and 187.50 respectively the objective function will remain optimal. This is in line with the findings of [14] that proposed feasible solution from an LP model of Port operations in Nigeria wherein the sensitivity analysis revealed similar trends.

It is pertinent to note that for variables, the reduced cost column reveals that for each variable which is currently zero $\mathrm{x} 1$ and $\mathrm{x} 2$ an estimate of how much the objective function will change if the variable is to be non zero. This value in the reduced cost column for a variable is often referred to as "the opportunity cost" for that variable. Hence the variable of $\mathrm{x} 3$ for TCCB of the objective function needs to change by 2600.00009 resulting to an increase, with respect to the maximization objective of the study. In other words, the profit per unit on the TCCB would need to increase by 2600.00009 before it would be profitable to produce any unit of boat $x 3$. This supports the work of [15].

Furthermore, by varying the coefficient of TCCB (x3) in the objective function, the allowable changes reveals that the coefficient of $\mathrm{x} 3$ in the objective function lies between $315,000+2600.000009$ and $315,000-1 \mathrm{E}+30$ while that of x2 lies between $256,800+23600=280,400$ and 256,800 $3250.000012=262,549.9999$. Hence the values of the variables of the linear programming solution will remain unchanged. Similar conclusions could be drawn from the NCPB $x 1$ unit with an allowable increase of 31,000 and allowable decrease of 3250.00001 thus $140,200-31,000$ and 140,200 $-3250.00001=\mathrm{N} 109,200$ and 136,949.9999 respectively. This is contrary to the works of [16] that proposed a new mathematical model for investigating course stability and maneuvering motions of sailing yachts using a 3D approach.
It is evidenced that when the cost of labour is increased by 100percent as wages, the solver gave an unchanged objective function of $\mathrm{N} 1,098,000$ showing there is no significant relationship between increased cost of labour and the boat building company. This equally supports the works of [15] and [5].

\section{CONCLUSION}

The major findings of this study reviewed the application of linear programming techniques in the building of marine boats gave a more practical and efficient approach to optimization of the model towards achieving higher profits and revealed which boat production boatyards should concentrate on. Hence the objectives were achieved as a higher profit margin was got from formally $\mathrm{N} \mathrm{712,000} \mathrm{to}$ $\mathrm{N} 1,080,000$, an appreciable profit margin of $\mathrm{N} 386,000$ representing a $54.3 \%$ increase in the profit as evidenced by the objective function in the model. The result further shows a significant reduction in wastage of materials and cost of production. Resin in particular was halved in quantity and model still got an optimal value of N1, 199,454.00 with the production of 3 NCPB and 3 TCPB and none for the TCCB.

Furthermore, sensitivity analysis reveals that a possible increase in workers' wages has no significant effect on the profit margin of the boatyard [17]. It could be inferred that, though un-utilized capacities abound, but for optimality the overall objective of profit maximization of the organization is achievable. However, it's of great interest to note also that, organizations should not only crave for profit maximization, but optimality. The implication of this is that, profit should be maximized at the lowest cost possible. Above all, the adjourning coastal communities would benefit from the multiplier effects arising from the operations of the boat yards not only for their economic survival but environmental sustainability. The reduction of wastages would go a long way to reduce liters on the coastal environment. Having met the objectives of this study, the agrarian communities would not only experience a boost in river transportation but as well enjoy employment and wage benefits offered by the boat building firms.

\section{ACKNOWLEDGMENTS}

I wish to express my profound gratitude to my MSc. Project Student Mr. k. A. Oke and the Staff and Management of TWASCO Marine Boat Building Company for their assistance in the provision of relevant data and materials for this work. Thank you.

\section{REFERENCES}

[1] S. C. Albright, and W. L. Winston, Management Science Modeling 4th ed. Delhi, India:South-Western, Cengage Learning, 2012, ch. 4, pp. 134- 195 .

[2] J.R.G. Souppez, "Structural design of high performance composite sailing yachts under the new BSEN ISO 12215-5". Journal of Sailing Technology, Vol. 3,no.1, pp. 1- 18, Jun. 2018.

[3] P.F. Hinrichsen, "Bifilar suspension Measurement of boat inertia parameters”. Journal of Sailing Technology,Vol. 3, no.1, pp. 1- 37, Dec. 2014

[4] B. Cadelen, F. Griffon, P. Lanusse, J. Sabatier and Y. Parlier, "Modelling and control of tethered kite in dynamic flight". Journal of Sailing Technology, vol. 3 no.4, pp. 1- 24, Jun. 2018. 
[5] M. Savsar, "Analysis and modeling of maintenance operations in the context of an oil filling plant". Journal of Manufacturing Technolog Management, Vol.22, no.5, pp. 679- 697, Jun. 2011

[6] S.O. Adebiyi, B.B. Amole and I. Soile, "Linear Optimization Techniques for Product- Mix of Paints Production in Nigeria". Acta Universitatis Danubus. Economica, vol. 10, no. 1,pp 181- 190, Feb. 2014.

[7] S. Khan, A. Bari and F.M. Khan, Linear and Integer Programming. U.K: Cambridge, 2019. Ch. 1, pp. 1- 15.

[8] P.K. Gupta, and D.S. Hira, Operations Research. New Delhi: S. Chand and Company Limited, 2012.ch. 1, pp. 1-20.

[9] J.Zang and R.Wang,"Research on the Marketing Strategy of New Energy Vehicles in SL Company". American Journal of Industrial and Business Management, vol. 9. no. 2. pp. 306 - 314, Feb. 2019.

[10] T. Ugbe and P. Chigbu, "Optimal Non- Overlapping Segmentation and Solutions of Three- Dimentional Linear Programming Problems through the Super Convergent Line Series". American Journal of Operations Research, vol. 7 no. 3, pp 225- 238, May 2017.

[11] B. Liao and S. Yu, " Research on the Ownership Structure Optimization and Corperate Governance Improvement of China's Large State- Owned Shipping Company after Integration". American Journal of Industrial and Business Management, vol. 9. no. 11. pp 1983 - 1994, Nov. 2019.

[12] A. Ramolini, "Implementation of a fluid - structure interaction solver for a spinner sail". Journal of Sailing Technology. vol. 4,no.1, pp. 116, Jun. 2019

[13] G.D. Aguilar, "The Philippine indigenous outrigger boat: Scaling up, performance and safety". Marine Technology Society Journal, vol.40, no. 3, pp. $49-58$, Sep. 2006.

[14] B.C. Asiegbu and I.C. Nze, "Optimization of Costs of Port Operations in Nigeria: a Scenario for Emerging River Ports", IISTRD West African Journal of Industrial \& Academic Research, vol. 6, no. 1, pp. 84- 91,Mar. 2013.

[15] J.Sobieszczanski-Sobieski, "Sensitivity analysis and multidisciplinary optimization for aircraft design: recent advances and results". Journal of Aircraft, vol. 27, no.12, pp. 993- 1001, Jul. 1990.

[16] M.Angelou and K.J. Spyrou, “ A new mathematical model for investigating course stability and maneuvering motions of sailing yachts". Journal of Sailing Technology, vol.6, no.1, pp. 1- 42, Sep. 2017.

[17] K.O. Agaviezor, "Application of Linear Programming Techniques in Optimization of Marine Boat Building Operations", M.Sc. thesis, Dept. Maritime Mgt. Tech., Federal Univ. of Tech., Owerri Nigeria, 2017.

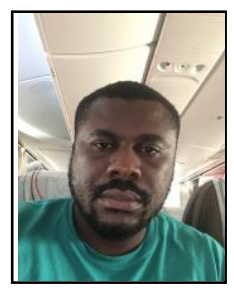

Ibeawuchi C. Nze a native of Amuzi- Ahiara in Imo State Nigeria; was born at Aboh on 25 February, 1978 and holds a Ph.D, M.Sc, and B.Tech degrees in Maritime Management Technology from the prestigious Federal University of Technology, Owerri Nigeria in 2015, 2008 and 2002 respectively. He is equally a Certified Advanced Software Technologist with CMC- TATA Academy, New Delhi India and a Certificate holder in Freight Forwarding, Supply Chain and Andragogy with Multimix Academy, Lagos Nigeria approved by the Council for Regulation of Freight Forwarding in Nigeria (CRFFN). He has been since 2016 a Senior Lecturer (and currently on assessment for Reader) in the Department of Maritime Management Technology, Federal University of Technology, Owerri Nigeria. He is widely published in local and international referred journals in over 20 publications with a book entitled: Economic Impact Assessment of Nigerian Ports- a disaggregate analysis. Latvia, Europe: Lambert Academic Publishing, 2018. Other articles include Cost optimization models of port operations in Nigeria- a scenario for emerging river ports. Spain: Journal of Maritime Research, vol. XIII. No. III (2016) pp 39- 46. www.jmr.unican.es; and Analysis of Fatality Rates of Boat and Ferry Accidents on Inland waterways in Nigeria. India: IOSR Journal of Business and Management Vol.11, Issue2,May-June,2013,pp17-20; to mention but a few.

Dr. Nze is an active member of renowned Professional bodies including the Society of Naval Architects and Marine Engineers (SNAME) USA, The Chartered Institute of Transport Administration (CIoTA) Nigeria, the Chartered Institute of Logistics and Transport (CILT) Nigeria as well as a Certified Trainer with the Council for Regulation of Freight Forwarding in Nigeria (CRFFN). A recipient of the World Bank STEP-B Innovators of Tomorrow grant for $\mathrm{PhD}$ research in 2010. Research interest includes modeling and Optimization of Maritime Transport Systems, Logistics as well as offshore operations. 